\title{
Informal Diplomacy Reinforces Formal International Cooperation: Evidence from Track Two Diplomacy ${ }^{*}$
}

\author{
Ted Hsuan Yun Chen
}

March 16, 2021

\begin{abstract}
Track two diplomacy is the set of government-sanctioned but informal diplomatic activities that are intended to overcome difficulties associated with formal diplomacy. Track two meetings should complement official diplomacy because they are external to the government apparatus and have low public visibility, insulating governments from unwanted commitment and attention. While track two meetings are a prevalent diplomatic tool, empirical examinations of their effectiveness using larger-scale statistical approaches are rare. Using a multilayer network approach, I explore the relationship between official and track two diplomacy in the Asia Pacific region using a new network data set constructed from diplomatic meeting records. Results indicate that the two tracks of diplomacy are mutually reinforcing, which suggests that track two diplomacy is effective in facilitating formal international cooperation. Further examination finds evidence to support the notion that states strategically select between different tracks of diplomacy to avoid being publicly tied to unpalatable opponents.
\end{abstract}

Keywords: international cooperation; track two diplomacy; informal diplomacy; network analysis; multilayer networks; Asia Pacific

${ }^{*}$ Ted Hsuan Yun Chen is a Postdoctoral Researcher at the Faculty of Social Sciences, University of Helsinki; and Department of Computer Science, Aalto University. I would like to thank Xun Cao, Bruce Desmarais, Paul Evans, Diane Felmlee, Scott Gartner, Mitch Goist, Boyoon Lee, Doug Lemke, Chuyu Liu, Kyung-ae Park, and participants at APSA 2017 for providing helpful feedback. Archival data used in this paper was graciously provided by Paul Evans at the University of British Columbia; the data in digitized format will be made available after publication at https://github.com/tedhchen. 


\section{Contents}

1 Introduction $\quad 1$

2 Track Two Effectiveness in Asia Pacific Integration 3

3 Data and Methods $\quad 5$

3.1 Dialogue and Research Monitor, 1993-2002 . . . . . . . . . . . . . . 6

3.2 Inferring Patterns of Diplomatic Cooperation among States . . . . . . . . 7

3.3 Multilayer Network of Formal and Informal Diplomacy . . . . . . . . . . . 9

3.4 Exponential Random Graph Models for Multilayer Networks . . . . . . . . . 10

3.4.1 Cross-layer Mutual Reinforcement . . . . . . . . . . . . . . . . . 12

3.4.2 Insulation Mechanism . . . . . . . . . . . . . . . . . . . . 12

3.4.3 Additional Model Terms . . . . . . . . . . . . . . . . 13

4 Results and Discussion $\quad 14$

5 Conclusion $\quad 16$

6 References $\quad 17$

A Robustness Checks $\quad 21$

B Model Fit Diagnostics $\quad 22$ 


\section{Introduction}

Track two diplomacy is the set of government-sanctioned but informal diplomatic activities that are intended to overcome difficulties associated with formal diplomacy (Davidson and Montville 1981; Montville 2006). Track two meetings vary in the topics they address, but are generally used for exploratory purposes (Jones 2015), and can occur either alongside or independently of official negotiations, usually with a low profile (Agha, Feldman and Khalidi 2003). Track two diplomacy has ostensibly had its share of successes facilitating interstate cooperation. Notably, the series of meetings that led to the Oslo Accords between Israel and Palestine began as a set of track two dialogues initiated by private citizens when official talks stalled (Agha, Feldman and Khalidi 2003). In general, the conflict resolution literature is optimistic about the prospects of track two diplomacy (Jones 2015; Böhmelt 2010; Ball, Milner and Taylor 2006). The prevailing understanding is that because track two meetings are low-commitment and not publicly salient, they are effective diplomatic tools for exploring sensitive areas of international politics (Jones 2015; Montville 2006).

These notions comport with our understanding of how commitment avoidance and secrecy influence international politics (e.g. Ramirez 2018; McManus and Yarhi-Milo 2017), but while track two meetings are a prevalent diplomatic tool, larger-scale statistical examinations of their effectiveness are rare (Böhmelt 2010). In one of the only statistical studies on this topic, Böhmelt (2010) finds that during third-party mediation to protracted conflicts, track two mediation have both independent as well as synergistic effects with track one (i.e. formal or official) efforts in increasing the likelihood of peaceful settlements. However, this is only one study, and it does not empirically address mechanisms proposed in the literature for track two effectiveness.

I add to this literature by showing that track one and track two meetings are mutually reinforcing features of the Asia Pacific diplomatic system, and offer evidence to support claims from the literature that track two works because they are able to insulate states from unwanted publicity. Besides being one of the first statistical examinations of this topic, my study makes a number of additional contributions to our understanding of track two effectiveness, and more generally how informal diplomacy facilitates international cooperation. First, I take advantage of recent developments in multilayer network modeling that is particularly suitable for analyzing the relationship between diplomatic cooperation across different tracks and temporal contexts (Chen 2019). Next, whereas the majority of prior track two research focused on the Middle East, I look at the Asia Pacific region. While diplomatic goals are often different across cases and regions, many aspects of the underlying relationships are comparable. Findings from additional geographic contexts therefore let us make broader and 
more robust conclusions.

My particular network approach and Asia Pacific focus allow me to make use of a previously unutilized data source. Specifically, I accessed archival data of Asia Pacific diplomatic meeting records from 1993 to 2002. This data was originally collected in real-time by policy and security studies experts in an effort to document track one and track two meetings to interested observers (Evans and Yue 1995). Its relative completeness provides a rare opportunity to systematically examine the effect of informal diplomacy in a broader setting outside of specific high-salience but rare cases like the Oslo Accords. Using advancements in network methods (Domagalski, Neal and Sagan 2021), I construct a new network data set from these diplomatic meeting records. ${ }^{1}$

My findings address broader topics in the international relations literature. First, the fact that track two meetings complement official diplomacy because of their low public profile adds to the recent interest in how secrecy matters to interactions between states (e.g. Myrick 2020; Otto and Spaniel 2020; McManus and Yarhi-Milo 2017; Carson 2016). Relatedly, commitment avoidance, as a part the audience cost literature, has been a central concept in international politics (Kurizaki 2007; Baum 2004). My study also relates to the research on epistemic communities (Haas 2015; Cross 2013), as participants to track two dialogues often come from a pool of experts who share principled beliefs about international governance (Simon 2002). I depart from the ideational mechanisms proposed in that literature, however, taking instead an information-based approach to explain track two efficacy. Finally, my study adds to the body of work on diplomatic networks (Kinne 2014; Maliniak and Plouffe 2011). Beyond these academic contributions, as one of the first large-scale statistical studies to show the relationship between the different track of diplomacy, my findings have immediate relevance for policy-makers and track two practitioners.

The remainder of this paper proceeds as follows. In the second section I provide a background of track two diplomacy in the Asia Pacific, and outline my theoretical expectations drawn from the informal diplomacy and track two literature. In the third section, I describe my empirical approach. First, I introduce a new network data set of formal and informal diplomatic ties coded from archival records of track one and two meetings in the Asia Pacific region. Then, I present a network approach based on the multilayer framework for studying interdependent relational systems such as diplomatic networks. In the fourth section, I present results from my network models of diplomatic cooperation. I show that, robust to standard control variables from the international politics literature, the two tracks of diplomacy are mutually reinforcing. Further, pairs of conflicting states are more likely to be diplomatically tied through track two channels than through track one channels, which

\footnotetext{
${ }^{1}$ The data will be available after publication at https://github.com/tedhchen.
} 
supports the notion that states strategically select between different tracks of diplomacy to avoid being publicly tied to unpalatable opponents.

\section{Track Two Effectiveness in Asia Pacific Integration}

Following the end of the Cold War, the Asia Pacific region witnessed increased efforts toward regional integration with a focus on multilateral institutions (Narine 2008; Kahler 2000). ${ }^{2}$ Despite these efforts, the level of formal and legal institutionalization remained weak (Kahler 2000; Johnston 2012). During this period, the push for regional integration came from the Association of Southeast Asian Nations (ASEAN), whose member states emphasized governance that broke from Cold War bloc politics and a strict adherence to noninterference norms (Acharya 1992, 2004). At the same time, historical legacies of ethnic conflict, territorial disputes, and colonialization between countries remained a highly-salient feature of international politics across subregions in Asia (Hemmer and Katzenstein 2002). Finally, a new superpower rivalry was developing between China and the U.S. (Ikenberry 2004). As a result, the strategic considerations surrounding Asia Pacific regional integration was characterized by high levels of intergroup mistrust and potential for domestic audience costs, making it similar to that of protracted conflicts. In these environments, even 'getting to the table' is difficult, as states tend to refrain from making strong political signals for both international and domestic reasons (McManus and Yarhi-Milo 2017; Kuo 2019).

To overcome these difficulties, states in the region engaged in what is known as track two diplomacy (Ball, Milner and Taylor 2006). This kind of informal diplomacy is generally understood to comprise exploratory (i.e. non-binding) meetings that are conducted, often behind closed-doors, by private citizens who are connected to the official government apparatus of the involved states (Jones 2015). While track two efforts are common in the Asia Pacific, assessments of their effectiveness to facilitate regional integration are mixed (Ball, Milner and Taylor 2006). For example, in a study of track two-induced ideational change, Capie (2010) found track two's influence on formal cooperation to wane over time. However, this study examined only the ideational aspect of track two diplomacy, leaving aside its procedural aspects which map well onto important mechanisms identified in the literature on secrecy and international cooperation.

Most importantly, while track two meetings are often not fully secret, they tend to be less visible to the public, especially when compared to official track one meetings. They are rarely

\footnotetext{
${ }^{2}$ The Asia Pacific region generally includes member states of the Association of Southeast Asian Nations; countries in Northeast Asia; countries in the Oceania region; Canada, Russia, and the U.S.; and sometimes countries from the Indian subcontinent. Table 1 contains the twenty-six states included in this study.
} 
covered in the mainstream media, and because their participants usually comprise academics and ex-officials, these meetings will often appear to the public as academic or think tank events (Kaye 2007). Accordingly, track two meetings register with only the most interested observers, then fade without entering the public purview. Similar to McManus and YarhiMilo's (2017) "offstage" signals, they let states split their audiences, allowing communication among relevant parties without incurring high public audience costs. Further, because track two participants are private citizens, governments have plausible deniability even if a meeting becomes highly publicized.

Insulation from audience cost can facilitate cooperation. As Ramirez (2018) showed, when the cost of noncooperation outweighs uncertainty, mediators operating in secrecy can reach cooperation that officials who fear sanction from domestic audiences would not negotiate for. On the other hand, where uncertainty is high, the noncommittal nature of track two diplomacy, which stems from its secrecy and nongovernmental participant pool, allows the relevant parties to explore policy boundaries, reducing the available policy-space into a subset (i.e. lower uncertainty) that is more political palatable to the states involved (Böhmelt 2010; Agha, Feldman and Khalidi 2003). Private citizens negotiating at an arm's length from official government apparatuses can uncover actors' resolve, thereby reducing uncertainty (Ramirez 2018). This obtains because explored outcomes can act as screening offers; while the cost of using track two is low due to insulation from audience cost, failed negotiation is costly because it returns the two sides to the undesirable noncooperation status quo. What track two does then, is facilitate low cost communication that allows states to coordinate on some mutually beneficial non-status quo outcome.

The immediate expectation from this discussion is that track two diplomacy will lead to increased formal cooperation. However, specifying this kind of one-way relationship misses the degree to which the two diplomatic tracks are joint processes (Diamond and McDonald 1996). Instead, the effectiveness of track two diplomacy must be studied in terms of its interdependence with formal diplomatic cooperation. This kind of relationship can be understood from a delegation framework where, in equilibrium, agents (i.e. track two participants) select only into scenarios where their efforts would not be rejected by the principal (Bendor, Glazer and Hammond 2001). While track two diplomacy works largely in part by being outside of the government apparatus, it is key that their participants remain connected to government officials because it facilitates information flow between the two tracks. This allows track two participants to anticipate acceptable areas of cooperation so as to avoid wasted efforts and falling out of favor with governments (Kaye 2007; Jones 2015). This means that not only will track two diplomacy facilitate track one cooperation, it will also be more abundant where there is track one cooperation. To examine this interdependent relationship, I posit 
the mutual reinforcement hypothesis:

Hypothesis 1: Formal diplomatic cooperation and track two cooperation will be mutually reinforcing.

In that formal governmental cooperation is the intended outcome of diplomatic dialogues, this measure is an encompassing one that yields observable implications that are broadly applicable to the varied contexts in which track two diplomacy is used.

In addition to looking at the tendency for the different diplomatic tracks to reinforce each other, I further look for evidence of the proposed mechanisms for track two effectiveness. From the discussion above, track two's effectiveness comes from its ability to insulate governments from costs associated with commitment and publicity. Following this, track two should be most likely where costs to formal public negotiations are high (McManus and Yarhi-Milo 2017; Ramirez 2018). To test this notion, I look at how the relative likelihood of track one and track two diplomacy varies by dyadic characteristics. In other words, I examine whether dyadic characteristics will differ in their impact on track two and track one cooperation. First, drawing on McManus and Yarhi-Milo (2017), who showed that the U.S. varied their on- and offstage signals depending on whether their diplomatic partner was a democracy or an autocracy, I test the insulation mechanism by comparing the importance of regime-similarity to the different diplomatic tracks. Second, I follow a similar logic and examine dyads that are in conflict. Because these two otherwise publicly-unpalatable dyadic characteristics are less likely to matter for track two diplomacy, we have the political insulation hypotheses:

Hypothesis 2: Mixed-regime dyads will be more likely to cooperate on track two than on track one.

Hypothesis 3: Conflicting dyads will be more likely to cooperate on track two than on track one.

\section{Data and Methods}

In this study, I take a network approach to studying the relationship between different tracks of diplomacy. Specifically, I measure mutual reinforcement between formal international cooperation and track two diplomacy by looking at the extent to which it contributes as a generative feature of the Asia Pacific diplomatic system. Using archival data of diplomatic meetings from 1993 to 2002, I construct networks where countries are connected to each other if they cooperate at formal and track two diplomatic levels. Network approaches are 
useful for studies in international relations (Cranmer and Desmarais 2016), and prior work have found network effects to play important roles in international diplomacy (Kinne 2014; Maliniak and Plouffe 2011). I advance the use of networks in diplomatic studies by using recent developments in network science to jointly model formal and informal diplomacy as a multilayer network (Chen 2019).

\subsection{Dialogue and Research Monitor, 1993-2002}

For my empirical analysis, I use data of formal and informal diplomatic meetings from the Dialogue Monitor and Dialogue and Research Monitor (Evans and Yue 1995). This data, which was published serially between 1995 and 2003, is a catalog of multilateral diplomatic meetings that took place among countries primarily from the Asia Pacific region and covers the 1993-2002 period. The data was collected in real time by policy and security studies experts, and is rich in detail. For each meeting, the research team documented the issue areas, the participating countries, when and where it took place, and its track (i.e. track two versus formal or 'track one'). For example, the following is an entry in the Track Two section of the first issue:

Asia Pacific Senior Seminar. (Honolulu, December 4-9, 1994.) Organized by the East-West Center and Pacific Forum/CSIS. Governmental and academic participants from Australia, China, France, India, Indonesia, Japan, Malaysia, New Zealand, Pakistan, Russia, Singapore, South Korea, the UN (Department of Political Affairs), USA, and Vietnam. Topics included security issues in the Asia Pacific region; new dimensions in security; regional community building; future trends in the Asia Pacific Region.

Between all issues published, this data collection documents in total 801 multilateral meetings pertaining to regional cooperation and security at the track one and track two levels. 172 of these meetings are at the track one level and 629 at the track two level. Figure 1 shows the geographical distribution of diplomatic participation at the track one and track two levels, in counts of meetings attended. States from all over the world make it to at least one of these meetings, but there is a core group from the Asia Pacific region, including states from East Asia, Oceania, the Indian subcontinent, and the U.S., Canada, and Russia, that are repeat participants in these meetings. Table 1 summarizes the twenty-six Asia Pacific states organized by their subregion and regime type.

Prior use of this data has been limited to descriptive trends (Acharya 2011; Job 2003), but the volume of this collection and the details it contains presents a rare opportunity to study the relationship between formal and informal diplomacy at a scale that is large enough 


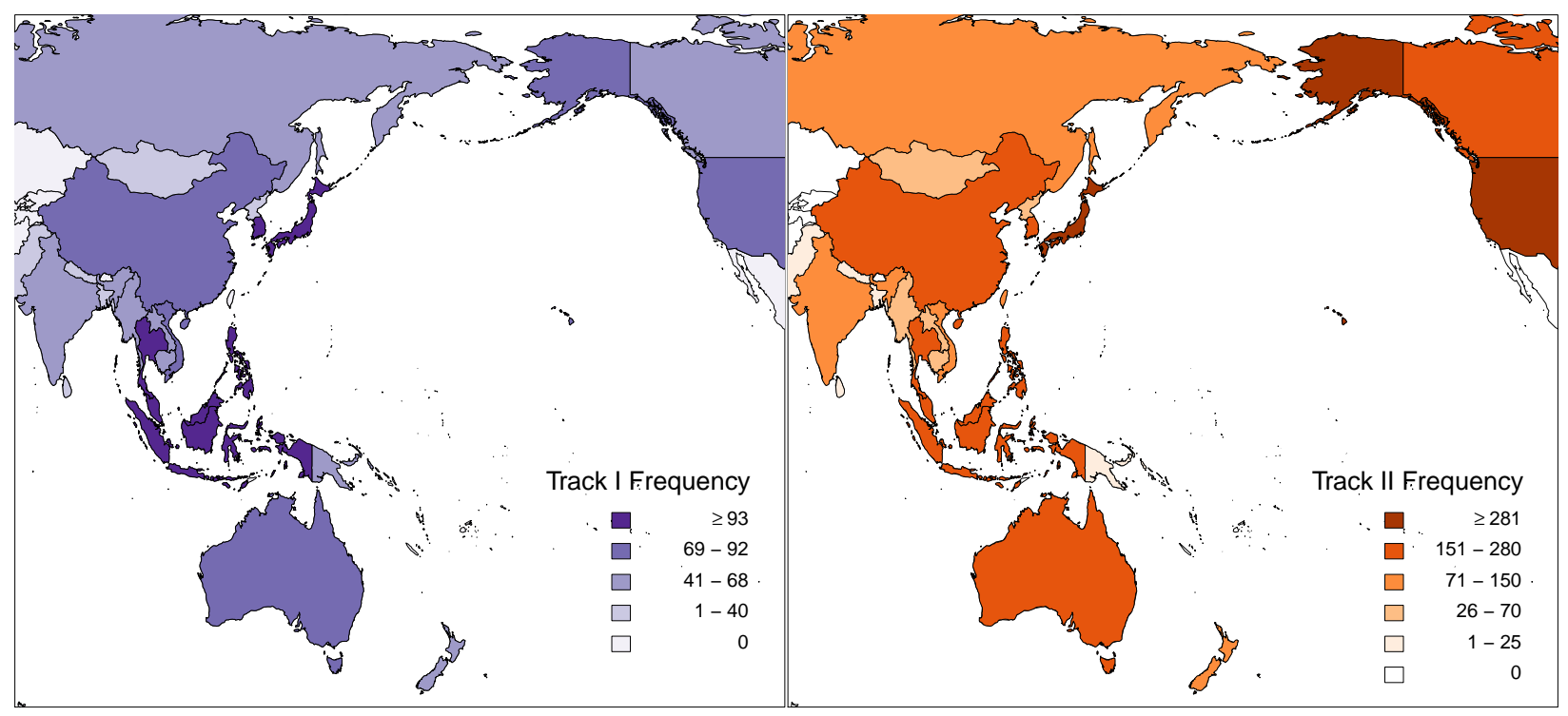

Figure 1: Distribution of track one and track two meeting participation in the Asia Pacific.

\begin{tabular}{|c|c|c|c|c|c|}
\hline & N. East Asia & S. Eas & Asia & South Asia & Other \\
\hline Democratic & $\begin{array}{l}\text { Japan } \\
\text { Mongolia } \\
\text { South Korea }\end{array}$ & $\begin{array}{l}\text { Indonesia } \\
\text { Philippines }\end{array}$ & Thailand & $\begin{array}{ll}\text { India } & \text { Pakistan } \\
\text { Nepal } & \text { Sri Lanka } \\
\text { Bangladesh }\end{array}$ & $\begin{array}{l}\text { Australia } \quad \text { Canada } \\
\text { New Zealand } \\
\text { PSA } \\
\text { Papua New Guinea }\end{array}$ \\
\hline $\begin{array}{l}\text { Non- } \\
\text { democratic }\end{array}$ & $\begin{array}{l}\text { China } \\
\text { North Korea }\end{array}$ & $\begin{array}{l}\text { Brunei } \\
\text { Laos } \\
\text { Myanmar } \\
\text { Cambodia }\end{array}$ & $\begin{array}{l}\text { Vietnam } \\
\text { Malaysia } \\
\text { Singapore }\end{array}$ & & Russia \\
\hline
\end{tabular}

Table 1: States in the Asia Pacific Region, by Subregion and Regime Type

for nuanced statistical inference, which can complement the existing largely qualitative literature. Before proceeding, it is pertinent to acknowledge that the data is not the complete set of all diplomatic meetings in the Asia Pacific. It is possible that unobserved bias entered into the data collection process. However, while it is important to be cognizant of the potential shortcomings of the data (see Ball and Kwa 2010, p. 159), as I show in the following section, the patterns of cooperation among countries from the Asia Pacific that can be inferred from the data has a high level of face validity as they comport with our general understanding of politics in the region.

\subsection{Inferring Patterns of Diplomatic Cooperation among States}

The information from the Dialogue and Research Monitor (DRM) in its most basic form is the attendance record of states at different multilateral diplomatic meetings over the course of ten years. This data structure is sometimes known as a bipartite network, which is defined 
as a network containing two disjoint sets of nodes (usually used to represent two different types of entities), with relational ties existing only between the two node sets and not within. In the present data set, state nodes are tied to meeting nodes through attendance, but no ties exist among states or among meetings.

Information from bipartite networks can be used to infer relationships within one set of nodes in the network, meaning that the result is a network of relations for a single type of nodes. Here, specifically, I use the attendance data to infer patterns of direct cooperation between states. This class of methods is known as bipartite projection, and is useful for this study because my purpose is to understand diplomatic cooperation among states rather than the determinants of diplomatic meeting attendance. Methods for bipartite projections vary primarily by the amount of information retained from the original bipartite network (Domagalski, Neal and Sagan 2021; Saracco et al. 2017; Neal 2014). I followed the fixed degree sequence model implemented by Domagalski, Neal and Sagan (2021), which incorporates attendance frequency from the perspective of both states and meetings when inferring connection strength. Under this projection method, simply attending the same meetings, even relatively frequently, is not necessarily evidence for meaningful cooperation. If the two states have a tendency to attend many meetings, or if the meetings they attend together are also attended by many other states, a higher number of joint-attendance is required before we can conclude that there is strong enough evidence of a true connection.

This method yields a diplomatic cooperation network on which a tie exists between two states if the frequency with which they jointly attend meetings is above a certain percentile threshold when compared to a null distribution. Technically, this is done using a curveball algorithm that shuffles the bipartite data matrix while preserving both row and column sums (i.e. total number of meetings attended by state and total number of state attendees by meeting). 10,000 simulations are used to generate a null distribution. To construct the final diplomatic cooperation network, I kept ties between state-pairs with observed values above the 80th percentile, but as shown in Appendix A, results presented in this paper hold for a range of reasonable threshold values.

The DRM data span a period of ten years from 1993 to 2002, and cover diplomatic meetings at different tracks. In order to study the interdependence between meetings at different diplomatic tracks and across time, I partition the data into subsets according to meeting track and time period before applying the projection method described. For meeting track, I follow the first and second track distinction coded by the DRM team. Temporally, the meetings are divided into calendar years. In the analysis, the 1993 networks are dropped in order to include temporally-lagged dependent variables in the model.

Results from this procedure yields diplomatic cooperation networks that resemble what 

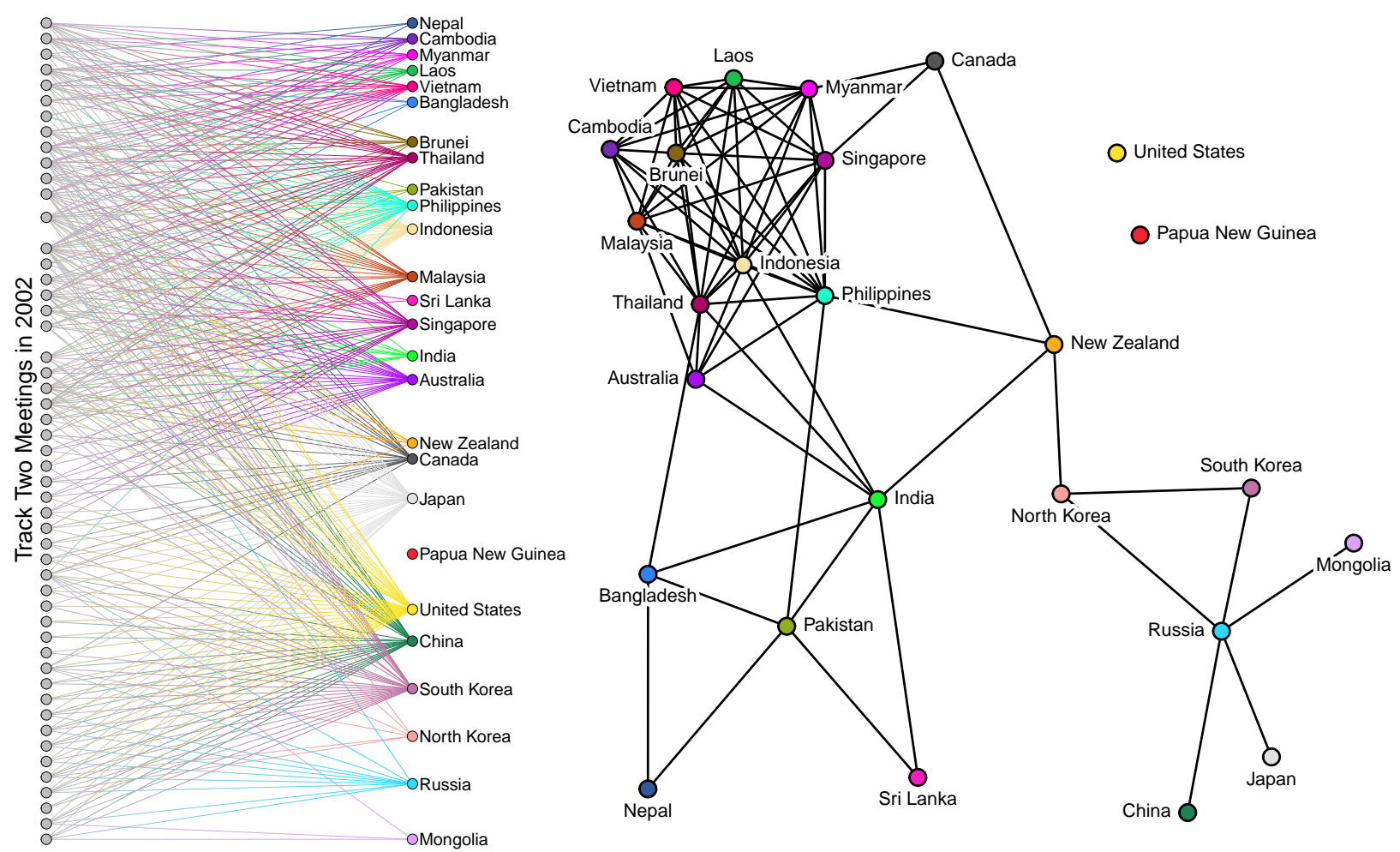

Figure 2: Track two cooperation between Asia Pacific states in 2002 (right) based on a bipartite projection of meeting records (left). The projection was done using a fixed degree sequence model that accounts for both the tendency of each state to attend meetings and for the inclusivity of each meeting.

we understand of diplomatic patterns in the Asia Pacific. Figure 2 shows the relationship between the raw data and inferred network for track two meetings in 2002. The most apparent aspect of the network is the dense clustering of ASEAN members, which are grouped toward the top left corner of the figure. There are other relatively dense clusters, which result from other subregional clusterings. Beyond this, there is some evidence of brokerage, with a number of relatively unconnected nodes tying together different regional clusters.

\subsection{Multilayer Network of Formal and Informal Diplomacy}

Applying bipartite projection to the partitioned DRM data subsets yielded twenty networks of diplomatic cooperation that differ by track and time period. In order to answer the questions posed (i.e. to what extent are the two tracks of diplomacy related?) I represent this set of twenty networks as a multilayer network, which allows me to jointly model them and account for the interdependence between them (i.e. cross-track and cross-time). Whereas networks traditionally treat ties as homogeneous, a multilayer network is a class of networks characterized by the existence of more than one type of tie (Kivelä et al. 2014). The Asia Pacific diplomacy system, in particular, is best represented as a multiplex network, a specific 


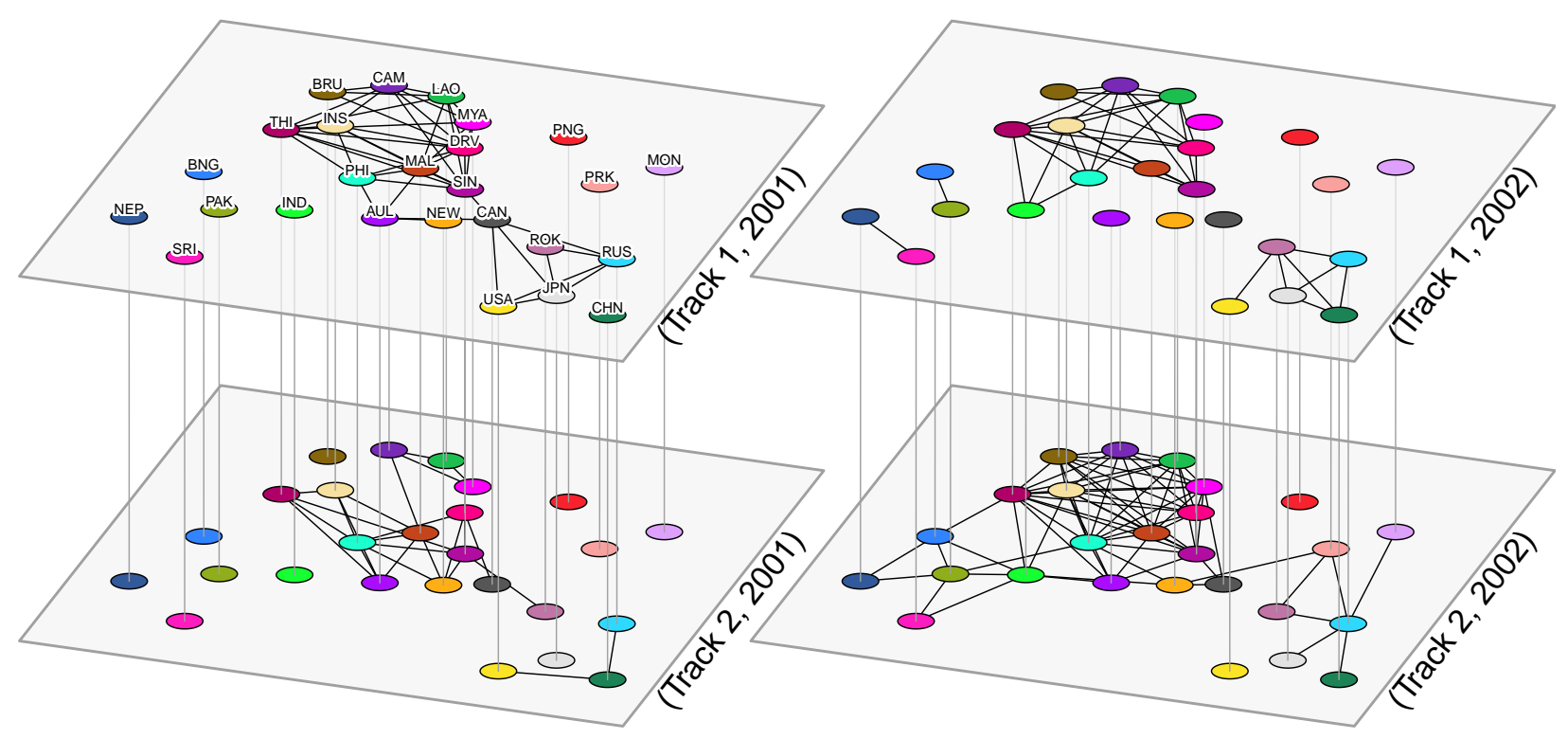

Figure 3: Multilayer network representation of the Asia Pacific diplomatic system, constructed using data from the Dialogue and Research Monitor. States are represented by the same colors and placed in the same positions across different layers. For visual clarity, only the 2001-2002 period is shown.

type of multilayer network that is useful for representing social and political systems in which one set of real-world entities interact across different relational contexts.

The organizing principle of multiplex networks, visualized in Figure 3, are network layers that represent each of the different relational contexts from a given system. These network layers are defined by a tuple of their context characteristics, and each real-world entity from the system is represented on each layer by a different node, which are connected across layers with an interlayer identifier tie, shown here with vertical lines. In the present case, the Asia Pacific diplomacy system has twenty (track, year) layers: \{(track one, 1993), (track two, 1993), (track one, 1994), ..., (track one, 2002), (track two, 2002)\}. Each of these network layers documents a different subcomponent of the body of formal and informal diplomatic cooperation that took place in the Asia Pacific region, as defined by the layer tuple. The real-world entities in this multilayer network are the twenty-six Asia Pacific states, and each appears once as a node on every layer.

\subsection{Exponential Random Graph Models for Multilayer Networks}

To model this multilayer network and statistically test the posited hypotheses, I use the exponential random graph model (ERGM). ERGMs are a class of models that allows for statistical inference on the factors that contribute to the generative process of an observed 
network (Cranmer and Desmarais 2011). These factors include covariates at the node and dyad level that are used in the classical regression framework, but also encompass network effects that capture the tendency for tie formation to depend on the presence of other ties in the network. ${ }^{3}$ Traditionally, ERGMs are limited by the assumption that all ties on the network are the same, but recent developments have extended the ERGM to multilayer networks (Chen 2019), which allows heterogeneous relational data to be jointly modelled. This extension to ERGMs is particularly suitable for my study, as the mutual reinforcement hypothesized to exist between different layers of the joint track one and track two multiplex network is a type of network effect, which I describe in more detail below.

In ERGMs, model terms for network effects are generally specified as counts of local network configurations (i.e. particular arrangement of ties connecting two or more nodes) over the entirety of the observed network. Because nodes are actors and ties are observed behavior, local network configurations can be used to capture joint behavioral tendencies among actors in a system. For example, in conflict studies where we expect conflicts dyads to cluster around specific actors, a 'star' configuration (i.e. multiple conflict dyads connected by a single actor node at the center) can be used to capture this tendency in the system that is being studied (Cranmer and Desmarais 2011).

Results from a fitted ERGM are estimates of the effect the specified factors have on the observed outcome. More specifically, model coefficients can be interpreted in the same way as those from a logistic regression model, as the change in log odds of a tie existing on a given dyad given a one unit increase in the model term. For most network effects, this means that the dyad constitutes a part of the term's corresponding local network configuration. Using this approach, I can assess whether the hypothesized mutual reinforcement effect across different tracks of diplomacy contributes in a statistically significant manner to patterns of cooperation in the Asia Pacific region. Further, because ERGMs can additionally include covariates at the node and dyad levels (e.g. country regime type and joint democracy), I can examine the political insulation mechanisms hypothesized for track two effectiveness by looking at whether the importance of certain dyadic covariates vary by track.

\footnotetext{
${ }^{3}$ In an ERGM, the probability of observing a network $\boldsymbol{Y}=\left\{Y_{i j}\right\}$, where $Y_{i j}=1$ indicates a tie between nodes $i$ and $j$, is specified as $\operatorname{Pr}(\boldsymbol{Y}, \boldsymbol{\theta})=\kappa^{-1} \exp \left\{\boldsymbol{\theta}^{\prime} \boldsymbol{x}(\boldsymbol{Y})\right\}$, where $\boldsymbol{\theta}$ is a vector of parameters and $\boldsymbol{x}$ is a vector function that yields a vector of observed network statistics computed on $\boldsymbol{Y} . \kappa=\sum_{\boldsymbol{Y}^{*} \in \mathcal{Y}} \exp \left\{\boldsymbol{\theta}^{\prime} \boldsymbol{x}\left(\boldsymbol{Y}^{*}\right)\right\}$, where $\mathcal{Y}$ is the set of all networks defined on the node set of $Y$, is the normalizing constant that makes the equation a proper probability distribution. Model terms are specified as elements in the vector $\boldsymbol{x}(\boldsymbol{Y})$, and are usually counts of local network configurations. See Cranmer and Desmarais (2011) for use of ERGMs in political science; and Chen (2019) for extensions to the multilayer framework.
} 


\subsubsection{Cross-layer Mutual Reinforcement}

The key question posed in this study is whether the two track of diplomacy are mutually reinforcing (H1). To test this hypothesis, I include a cross-layer alignment term that captures the tendency for cross-track mutual reinforcement. This is a kind of network effect which, as noted, is modeled in ERGMs using local network configurations, or patterns of observed relational behavior. The configuration that captures this mutual reinforcement effect is the cross-layer alignment configuration (Wang et al. 2013), graphically shown in Figure 4. This configuration captures an actor-pair (i.e. two states) tied (i.e. cooperating) in two contexts, represented by four nodes (i.e. two for each actor) on two layers of the network (i.e. one for each context).

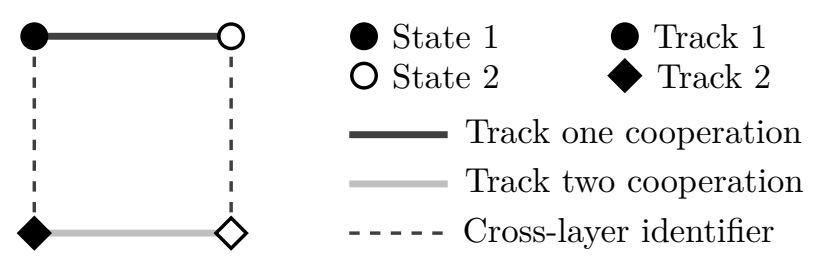

Figure 4: Representation of the cross-layer alignment configuration.

Again, the ERGM is highly suitable for my study because its flexibility to include network effects as local network configurations allow cooperation at both tracks to be jointlymodelled, yielding a statistically-valid estimate of their importance to each other and to the overall diplomatic system. The abundance of this type of configuration on the network, conditional on other features specified in the model, means that cooperation in the two different contexts are mutually reinforcing; the presence of track one cooperation means track two cooperation is more likely and vice versa.

\subsubsection{Insulation Mechanism}

To examine the set of political insulation mechanisms (H2 and H3), I include dyad-level terms for mixed-regime dyads and dyads in conflict. The data used to construct these terms respectively come from the Democracy and Dictatorship data set (Cheibub, Gandhi and Vreeland 2010) and the dyadic militarized interstate dispute data set (Maoz et al. 2019). The mixed-regime term captures the extent to which these dyads are more likely to cooperate, compared to joint-democracies and joint-autocracies. The dyad in conflict term, on the other hand, captures the likelihood of conflicting dyads to form diplomatic ties, compared to nonconflicting dyads. The expectation posited above is that because these publicly-unpalatable dyadic characteristics inhibit formal cooperation on the track one level, dyads with these characteristics will be more likely to form diplomatic ties at the track two level, where they 
are relatively insulated from public scrutiny. In my analysis, I assess this expectation by considering whether allowing the generative effect of these dyadic characteristics to vary by track produces better fitting models.

Specifically, in two separate models, I include track-specific terms for mixed-regimes and for conflicting dyads. This can be understood as including an interaction term between diplomatic track and the given dyadic characteristic (i.e. they are equivalent models). Then, the fit of these models with the interaction terms can be tested against the fit of the baseline model to determine whether these dyadic considerations differ by track. Here, better fitting expanded models indicate support for the insulation mechanism, especially if the track two term is larger than the track one term.

\subsubsection{Additional Model Terms}

My model specification includes additional factors that contribute to tie formation in the Asia Pacific diplomatic network. First, I include a set of homophily terms based on the subregions from Table 1, which capture the tendency for states from the same subregions to form cooperative ties. As the inferred network plot from Figure 2 shows, states in the same subregion are highly likely to be connected, often forming near-cliques where cooperative ties are nearly saturated.

Next, I include a set of terms common to international politics research. At the statelevel, I include total trade volume and trade embeddedness (calculated as total trade volume as a proportion of GDP). At the dyad-level, I include terms for preference similarity based on treaty commitments (Lupu 2016) and voting in the UN General Assembly (Bailey, Strezhnev and Voeten 2017), and finally a term for border sharing (by land or up to 24 miles by water, see Stinnett et al. 2002), which should be a strong predictor for diplomatic ties as shared borders are a source of increased interaction and issues that need to be solved. As I show in Appendix A, these standard covariates improve model fit but do not affect results for the three hypothesis tests. I also include two additional network terms at the track one and track two levels that capture the tendency for diplomatic ties to cluster. Specifically, these are geometrically-weighted degree (GW degree) terms common to ERGMs (Snijders et al. 2006). A negative coefficient on these terms indicate clustering (Levy 2016).

Finally, I include a set of terms specific to the Asia Pacific context. At the track one level, homophily and GW degree terms for ASEAN countries captures the expected tendency for ASEAN states to be closely tied. Similarly, at the track two level, I include homophily and GW degree terms for states who are members of the Council for Security Cooperation in the Asia Pacific (CSCAP). The CSCAP is a track two coordination mechanism in the Asia Pacific. Similar to state participation in ASEAN meetings at the track one level, the 
CSCAP schedules regular meetings for its member organizations, which primarily comprise the track two actors associated with Asia Pacific states (Ball and Kwa 2010). Joint-CSCAP membership should therefore be an important predictor of track two cooperation. Lagged outcomes are included in all model specifications.

\section{Results and Discussion}

Results from the fitted models are reported in Table 2. ${ }^{4}$ Model fit diagnostics, shown in Appendix B, indicate sufficiently good fit to the data. The reported results can be interpreted in the same manner as those from a logistic regression. Coefficient are estimates of the change in log odds of a tie forming on a dyad for a one unit increase in the model term, conditional on all other modeled effects. Deviance is a measure of model fit, computed from the likelihood. These values can be compared directly across nested models (all except for models III and IV), and tested using a $\chi^{2}$ distribution to determine whether the larger models are justified.

To test the mutual reinforcement hypothesis (H1), I first fit a baseline model (I) that does not account for the interdependence between track one and track two ties, and a constrained cross-layer model (II) that adds the cross-layer alignment term shown in Figure 4. A comparison between these two models shows evidence supporting the mutual reinforcement hypothesis. Specifically, the inclusion of the cross-layer alignment term, which captures the tendency for the two diplomatic tracks to be mutually reinforcing, improves the model fit. Model II has a lower deviance than model I, a difference that is statistically significant when tested against a $\chi^{2}$ distribution with one degree of freedom. Further, the estimated coefficient on the cross-layer alignment term is positive (highlighted in gray), indicating that that conditional on all other modeled effects, track two cooperation between two states increases the likelihood of these states forming a track one tie. At the same time, this also means that the presence of track one cooperation increases the likelihood of observing a track two tie between these states.

Next, I test the political insulation hypotheses (H2 and H3) by fitting two additional models that respectively allow the effects of mixed regimes (III) and dyadic conflict (IV) to vary across the two diplomatic tracks. This is equivalent to fitting models with interaction terms between the dyadic effects and the diplomatic track. Comparing these models to model II, which constrains the two dyadic considerations to have a constant effect on track one and track two diplomacy, I find conditional support for the political insulation hypotheses.

First, consider the effect of dyadic conflict on diplomatic cooperation (H3). In model II,

\footnotetext{
${ }^{4}$ All models were fit in R (R Core Team 2021) using the ergm (Handcock et al. 2020) and multilayer.ergm (Chen 2020) packages.
} 


\begin{tabular}{|c|c|c|c|c|c|c|c|c|}
\hline \multirow[b]{3}{*}{ Term } & \multicolumn{2}{|c|}{$\mathrm{I}$} & \multicolumn{2}{|c|}{ II } & \multicolumn{2}{|c|}{ III } & \multirow{2}{*}{\multicolumn{2}{|c|}{$\begin{array}{c}\text { IV } \\
\text { Conflict Dyad }\end{array}$}} \\
\hline & \multicolumn{2}{|c|}{ Base } & \multicolumn{2}{|c|}{ Constrained } & \multicolumn{2}{|c|}{ Mixed Regime } & & \\
\hline & coef. & s.e. & coef. & s.e. & coef. & s.e. & coef. & s.e. \\
\hline (T1) Edges & $-2.93^{*}$ & 0.59 & $-2.93^{*}$ & 0.58 & $-2.89^{*}$ & 0.58 & $-2.93^{*}$ & 0.59 \\
\hline (T2) Edges & $-3.25^{*}$ & 0.58 & $-3.20^{*}$ & 0.56 & $-3.26^{*}$ & 0.57 & $-3.22^{*}$ & 0.57 \\
\hline (T1) GW Degree & $-2.44^{*}$ & 0.32 & $-2.38^{*}$ & 0.32 & $-2.41^{*}$ & 0.33 & $-2.30^{*}$ & 0.33 \\
\hline (T2) GW Degree & $-2.69 *$ & 0.44 & $-2.63^{*}$ & 0.44 & $-2.60^{*}$ & 0.44 & $-2.65^{*}$ & 0.44 \\
\hline (T1) GW Degree (ASEAN) & $-2.11^{*}$ & 0.40 & $-2.20^{*}$ & 0.41 & $-2.17^{*}$ & 0.41 & $-2.28^{*}$ & 0.41 \\
\hline (T2) GW Degree (CSCAP) & 0.03 & 0.54 & 0.00 & 0.54 & -0.02 & 0.54 & 0.00 & 0.54 \\
\hline (T1) ASEAN Homophily & $0.87^{*}$ & 0.22 & $0.76^{*}$ & 0.22 & $0.77^{*}$ & 0.22 & $0.75^{*}$ & 0.24 \\
\hline (T2) CSCAP Homophily & $0.90^{*}$ & 0.20 & $0.92^{*}$ & 0.20 & $0.91^{*}$ & 0.20 & $0.93^{*}$ & 0.20 \\
\hline Northeast Asian Homophily & $1.23^{*}$ & 0.24 & $1.19^{*}$ & 0.24 & $1.19^{*}$ & 0.24 & $1.15^{*}$ & 0.24 \\
\hline Southeast Asian Homophily & $2.51^{*}$ & 0.17 & $2.41^{*}$ & 0.17 & $2.42^{*}$ & 0.17 & $2.43^{*}$ & 0.17 \\
\hline South Asian Homophily & $2.26^{*}$ & 0.24 & $2.18^{*}$ & 0.24 & $2.16^{*}$ & 0.24 & $2.19^{*}$ & 0.24 \\
\hline State Trade Volume & $0.05^{*}$ & 0.02 & $0.04^{*}$ & 0.02 & $0.04^{*}$ & 0.02 & $0.04^{*}$ & 0.02 \\
\hline State Embeddedness & 0.01 & 0.05 & 0.01 & 0.05 & 0.01 & 0.05 & 0.01 & 0.05 \\
\hline Treaty Distance & -0.26 & 0.14 & -0.24 & 0.14 & -0.25 & 0.14 & -0.24 & 0.14 \\
\hline UNGA Voting Distance & 0.00 & 0.07 & 0.00 & 0.07 & 0.00 & 0.07 & 0.00 & 0.07 \\
\hline Geographical Contiguity & $0.43^{*}$ & 0.16 & $0.41^{*}$ & 0.15 & $0.41^{*}$ & 0.15 & $0.41^{*}$ & 0.15 \\
\hline Democracy & $0.30^{*}$ & 0.08 & $0.29 *$ & 0.08 & $0.30^{*}$ & 0.08 & $0.29 *$ & 0.08 \\
\hline Mixed Regime & $-0.35^{*}$ & 0.11 & $-0.35^{*}$ & 0.11 & & & $-0.35^{*}$ & 0.11 \\
\hline (T1) Mixed Regime & & & & & $-0.52^{*}$ & 0.20 & & \\
\hline (T2) Mixed Regime & & & & & $-0.27^{*}$ & 0.14 & & \\
\hline Conflict Dyad & 0.16 & 0.26 & 0.15 & 0.26 & 0.15 & 0.26 & & \\
\hline (T1) Conflict Dyad & & & & & & & -0.83 & 0.54 \\
\hline (T2) Conflict Dyad & & & & & & & 0.52 & 0.30 \\
\hline cross-layer Alignment & & & $0.41^{*}$ & 0.18 & $0.40^{*}$ & 0.18 & $0.43^{*}$ & 0.19 \\
\hline Lagged Outcome & & luded & & uded & & uded & Inc & ded \\
\hline Deviance $(\Delta$ d.f. $)$ & & $.5(0)$ & 2430 & $9(-1)$ & 2430 & $2(-2)$ & 2425 & $(-2)$ \\
\hline$P\left(\chi_{1}^{2} \geq \Delta D\right)$ & & - & & 031 & & 403 & & \\
\hline
\end{tabular}

* on the coefficient indicates $p<0.05$. The decay parameters for the GW degree terms are set to $\theta_{s}=1$. $P\left(\chi_{1}^{2} \geq \Delta D\right)$ is the $p$-value for the test for model selection; model II is compared against the smaller model I, and models III and IV are compared against the smaller model II. In both cases, the expanded models have one more term than the constrained one, so the $\chi^{2}$ distribution has one degree of freedom.

Table 2: ERGMs for Asia Pacific Diplomatic Cooperation, 1994-2002

the conflict dyad term, which constrains its effect to be the same across the two diplomatic tracks, is statistically indistinguishable from zero (highlighted in green). In model IV, however, when the effect is allowed to vary, a stark contrast emerges. The difference between the coefficient estimates on the track one and track two terms (highlighted in green) indicates that track two cooperation is much more likely than track one cooperation when two states are engaged in conflict. This difference, tested by looking at model IV's improved fit over model II (i.e. lower deviance), is statistically significant. This finding supports the notion 
that track two diplomacy provides insulation to states that do not want to incur the costs of diplomatically engaging politically unpalatable opponents in a public manner.

Results from the mixed regime examination (H2), on the other hand, does not offer clear evidence supporting this notion. In model II, the mixed regime term has a negative coefficient (highlighted in blue), indicating that, as generally expected, mixed regime dyads are less likely to be diplomatically tied when compared to joint-democracies and joint-autocracies. Allowing the effect of mixed regimes to vary by track in model III, however, does not significantly improve model fit, which means that there is no statistically distinguishable difference between the two tracks in terms of mixed regime dyads becoming diplomatically tied. This comparison indicates that while mixed types are indeed less likely to cooperate diplomatically, there is no evidence to show that they try to avoid public scrutiny via track two channels.

\section{Conclusion}

Track two diplomacy is a prevalent diplomatic tool that is used across the world. There are obvious instances of track two success, but the overall effectiveness of track two meetings had rarely been studied using a larger-scale, statistical approach. In this study I took a multilayer network modeling approach to examine the relationship between track one and track two diplomacy in the Asia Pacific region. Results indicate strong support for positive mutual reinforcement as a generative feature of the regional diplomatic cooperation network. Specifically, I found that the pairs of states engaged in track two diplomacy are more likely to also be engaged in track one diplomacy, and vice versa. I take this to be evidence for the effectiveness of track two diplomacy, as the low trust and high audience cost environment of post-Cold War Asia Pacific means that public displays of track one diplomatic cooperation can be difficult to achieve. Further examination shows conditional support for the notion that track two diplomacy complements formal diplomacy because its low public visibility insulates states from unwanted domestic audience costs. While dyadic regime considerations do not differ by diplomatic tracks, pairs of states that are in conflict with each other are more likely to cooperate through track two channels than track one channels, suggesting that in some scenarios states strategically select between tracks of diplomacy.

The approach in this paper extends well to future work, hopefully opening new avenues of research into quantitative diplomatic studies. In my examination, I focused on a particular aspect of diplomacy, but the data supports further related work. For example, whereas international cooperation in this study is limited to 'getting to the table', future work can look into how formal and informal diplomatic ties relate to concrete policy convergence or 
direct cooperation by combining this data set with other network data. Methodologically, as the first study to use a multilayer network approach to examine the relationship between different tracks of diplomacy, this study illustrates the utility of network approaches to understanding diplomatic relations. Network approaches are an intuitively appealing way to study diplomatic relationships, and the multilayer approach provides further flexibility to jointly model the interdependence between different types of relational outcomes beyond those used in this study.

\section{References}

Acharya, Amitav. 1992. "Regional Military-Security Cooperation in the Third World: A Conceptual Analysis of the Relevance and Limitations of ASEAN (Association of Southeast Asian Nations)." Journal of Peace Research 29(1):7-21.

Acharya, Amitav. 2004. "How Ideas Spread: Whose Norms Matter? Norm Localization and Institutional Change in Asian Regionalism." International Organization 58(02):239-275.

Acharya, Amitav. 2011. "Engagement or Entrapment? Scholarship and Policymaking on Asian Regionalism." International Studies Review 13(1):12-17.

Agha, Hussein, Shai Feldman and Ahmad Khalidi. 2003. Track-II Diplomacy: Lessons from the Middle East. MIT Press.

Bailey, Michael A, Anton Strezhnev and Erik Voeten. 2017. "Estimating dynamic state preferences from United Nations voting data." Journal of Conflict Resolution 61(2):430456.

Ball, Desmond, Anthony Milner and Brendan Taylor. 2006. "Track 2 Security Dialogue in the Asia-Pacific: Reflections and Future Directions." Asian Security 2(3):174-188.

Ball, Desmond and Chong Guan Kwa. 2010. Assessing Track 2 Diplomacy in the Asia-Pacific Region: A CSCAP Reader. S. Rajaratnam School of International Studies.

Baum, Matthew A. 2004. "Going private: Public opinion, presidential rhetoric, and the domestic politics of audience costs in US foreign policy crises." Journal of Conflict Resolution 48(5):603-631.

Bendor, Jonathan, Amihai Glazer and Thomas Hammond. 2001. "Theories of Delegation." Annual Review of Political Science 4(1):235-269.

Böhmelt, Tobias. 2010. "The Effectiveness of Tracks of Diplomacy Strategies in Third-Party Interventions." Journal of Peace Research 47(2):167-178.

Capie, David. 2010. "When Does Track Two Matter? Structure, Agency and Asian Regionalism." Review of International Political Economy 17(2):291-318. 
Carson, Austin. 2016. "Facing off and saving face: covert intervention and escalation management in the Korean War." International Organization pp. 103-131.

Cheibub, José Antonio, Jennifer Gandhi and James Raymond Vreeland. 2010. "Democracy and dictatorship revisited." Public choice 143(1):67-101.

Chen, Ted Hsuan Yun. 2019. "Statistical inference for multilayer networks in political science." Political Science Research and Methods pp. 1-18.

Chen, Ted Hsuan Yun. 2020. multilayer.ergm: Exponential Random Graph Models for Multilayer Networks. R package version 0.2.0.

URL: https://github.com/tedhchen/multilayer.ergm

Cranmer, Skyler J and Bruce A Desmarais. 2011. "Inferential Network Analysis with Exponential Random Graph Models." Political Analysis 19(1):66-86.

Cranmer, Skyler J and Bruce A Desmarais. 2016. "A Critique of Dyadic Design." International Studies Quarterly 60(2):355-362.

Cross, Mai'a K Davis. 2013. "Rethinking Epistemic Communities Twenty Years Later." Review of International Studies 39:137-160.

Davidson, William D and Joseph V Montville. 1981. "Foreign Policy According to Freud." Foreign Policy 45:145-157.

Diamond, Louise and John W McDonald. 1996. Multi-Track Diplomacy: A Systems Approach to Peace. Kumarian Press.

Domagalski, Rachel, Zachary P Neal and Bruce Sagan. 2021. "Backbone: An R package for extracting the backbone of bipartite projections." Plos one 16(1):e0244363.

Evans, Paul and Shirley Yue. 1995. Dialogue Monitor: Inventory of Multilateral Meetings on Asia Pacific Security Issues. University of Toronto-York University Joint Centre for Asia Pacific Studies.

Haas, Peter M. 2015. Epistemic Communities, Constructivism, and International Environmental Politics. Routledge.

Handcock, Mark S., David R. Hunter, Carter T. Butts, Steven M. Goodreau, Pavel N. Krivitsky and Martina Morris. 2020. ergm: Fit, Simulate and Diagnose Exponential-Family Models for Networks. The Statnet Project (https://statnet.org). R package version 3.11.0.

URL: https://CRAN.R-project.org/package=ergm

Hemmer, Christopher and Peter J Katzenstein. 2002. "Why is There No NATO in Asia? Collective Identity, Regionalism, and the Origins of Multilateralism." International Organization 56(03):575-607.

Ikenberry, G John. 2004. "American Hegemony and East Asian Order." Australian Journal of International Affairs 58(3):353-367. 
Job, Brian L. 2003. Track 2 diplomacy: Ideational contribution to the evolving Asian security order. In Asian security order: Instrumental and normative features, ed. Muthiah Alagappa. Stanford University Press pp. 241-279.

Johnston, Alastair Iain. 2012. "What (if anything) does East Asia tell us about international relations theory?" Annual Review of Political Science 15:53-78.

Jones, Peter. 2015. Track Two Diplomacy in Theory and Practice. Stanford University Press.

Kahler, Miles. 2000. "Legalization as strategy: the Asia-Pacific case." International Organization pp. 549-571.

Kaye, Dalia Dassa. 2007. Talking to the Enemy: Track Two Diplomacy in the Middle East and South Asia. Rand Corporation.

Kinne, Brandon J. 2014. "Dependent diplomacy: Signaling, strategy, and prestige in the diplomatic network." International Studies Quarterly 58(2):247-259.

Kivelä, Mikko, Alex Arenas, Marc Barthelemy, James P Gleeson, Yamir Moreno and Mason A Porter. 2014. "Multilayer networks." Journal of complex networks 2(3):203-271.

Kuo, Raymond. 2019. "Secrecy among Friends: Covert Military Alliances and Portfolio Consistency." Journal of Conflict Resolution p. 0022002719849676.

Kurizaki, Shuhei. 2007. "Efficient Secrecy: Public Versus Private Threats in Crisis Diplomacy." American Political Science Review 101(03):543-558.

Levy, Michael A. 2016. "gwdegree: Improving interpretation of geometrically-weighted degree estimates in exponential random graph models." Journal of Open Source Software 1(3):36.

Lupu, Yonatan. 2016. "Why Do States Join Some Universal Treaties but not Others? an Analysis of Treaty Commitment Preferences." Journal of Conflict Resolution 60(7):12191250 .

Maliniak, Daniel and Michael Plouffe. 2011. A network approach to the formation of diplomatic ties. In APSA 2011 Annual Meeting paper.

Maoz, Zeev, Paul L Johnson, Jasper Kaplan, Fiona Ogunkoya and Aaron P Shreve. 2019. "The dyadic militarized interstate disputes (MIDs) dataset version 3.0: Logic, characteristics, and comparisons to alternative datasets." Journal of Conflict Resolution 63(3):811835 .

McManus, Roseanne W and Keren Yarhi-Milo. 2017. "The Logic of "Offstage" Signaling: Domestic Politics, Regime Type, and Major Power-Protégé Relations." International Organization 71(4):701-733.

Montville, Joseph V. 2006. "Track Two Diplomacy: The Work of Healing History." Whitehead Journal of Diplomacy \& International Relations 7:15. 
Myrick, Rachel. 2020. "Why So Secretive? Unpacking Public Attitudes toward Secrecy and Success in US Foreign Policy." The Journal of Politics 82(3):000-000.

Narine, Shaun. 2008. "Forty Years of ASEAN: a Historical Review." The Pacific Review 21(4):411-429.

Neal, Zachary. 2014. "The backbone of bipartite projections: Inferring relationships from coauthorship, co-sponsorship, co-attendance and other co-behaviors." Social Networks 39:8497.

Otto, Jacob and William Spaniel. 2020. "Doubling Down: The Danger of Disclosing Secret Action." International Studies Quarterly .

R Core Team. 2021. R: A Language and Environment for Statistical Computing. Vienna, Austria: R Foundation for Statistical Computing.

URL: https://www.R-project.org/

Ramirez, Shawn L. 2018. "Mediation in the shadow of an audience: How third parties use secrecy and agenda-setting to broker settlements." Journal of Theoretical Politics 30(1):119146.

Saracco, Fabio, Mika J Straka, Riccardo Di Clemente, Andrea Gabrielli, Guido Caldarelli and Tiziano Squartini. 2017. "Inferring monopartite projections of bipartite networks: an entropy-based approach." New Journal of Physics 19(5):053022.

Simon, Sheldon W. 2002. "Evaluating Track II Approaches to Security Diplomacy in the Asia-Pacific: The CSCAP Experience." The Pacific Review 15(2):167-200.

Snijders, Tom AB, Philippa E Pattison, Garry L Robins and Mark S Handcock. 2006. "New Specifications for Exponential Random Graph Models." Sociological Methodology 36(1):99153.

Stinnett, Douglas M, Jaroslav Tir, Paul F Diehl, Philip Schafer and Charles Gochman. 2002. "The Correlates of War (COW) Project Direct Contiguity Data, Version 3.0." Conflict Management and Peace Science 19(2):59-67.

Wang, Peng, Garry Robins, Philippa Pattison and Emmanuel Lazega. 2013. "Exponential Random Graph Models for Multilevel Networks." Social Networks 35(1):96-115. 


\section{A Robustness Checks}

\begin{tabular}{|c|c|c|c|c|c|c|c|c|}
\hline \multirow[b]{2}{*}{ Term } & \multicolumn{2}{|c|}{ Base } & \multicolumn{2}{|c|}{$\underline{\text { Constrained }}$} & \multicolumn{2}{|c|}{$\underline{\text { Mixed Regime }}$} & \multicolumn{2}{|c|}{ Conflict Dyad } \\
\hline & coef. & s.e. & coef. & s.e. & coef. & s.e. & coef. & s.e. \\
\hline Mixed Regime & $-0.36^{*}$ & 0.11 & $-0.35^{*}$ & 0.11 & & & $-0.35^{*}$ & 0.11 \\
\hline (T1) Mixed Regime & & & & & $-0.49 *$ & 0.18 & & \\
\hline (T2) Mixed Regime & & & & & $-0.29 *$ & 0.14 & & \\
\hline Conflict Dyad & 0.43 & 0.25 & 0.40 & 0.24 & 0.41 & 0.24 & & \\
\hline (T1) Conflict Dyad & & & & & & & -0.57 & 0.53 \\
\hline (T2) Conflict Dyad & & & & & & & $0.77^{*}$ & 0.28 \\
\hline cross-layer Alignment & & & $0.48^{*}$ & 0.18 & $0.47^{*}$ & 0.17 & $0.51^{*}$ & 0.19 \\
\hline
\end{tabular}

(Additional model terms not shown; international politics covariates omitted.)

\begin{tabular}{rcccc} 
Deviance $(\Delta$ d.f. $)$ & $2455.8(0)$ & $2449.1(-1)$ & $2448.5(-2)$ & $2443.6(-2)$ \\
$P\left(\chi_{1}^{2} \geq \Delta D\right)$ & - & 0.010 & 0.412 & 0.018 \\
\hline
\end{tabular}

* on the coefficient indicates $p<0.05$. The decay parameters for the GW degree terms are set to $\theta_{s}=1$. $P\left(\chi_{1}^{2} \geq \Delta D\right)$ is the $p$-value for the test for model selection; model II is compared against the smaller model I, and models III and IV are compared against the smaller model II. In both cases, the expanded models have one more term than the constrained one, so the $\chi^{2}$ distribution has one degree of freedom.

Table A1: ERGMs for Asia Pacific diplomatic cooperation, with common international politics covariates omitted. The substantive results reported in the main text are robust to the omission of these model terms.

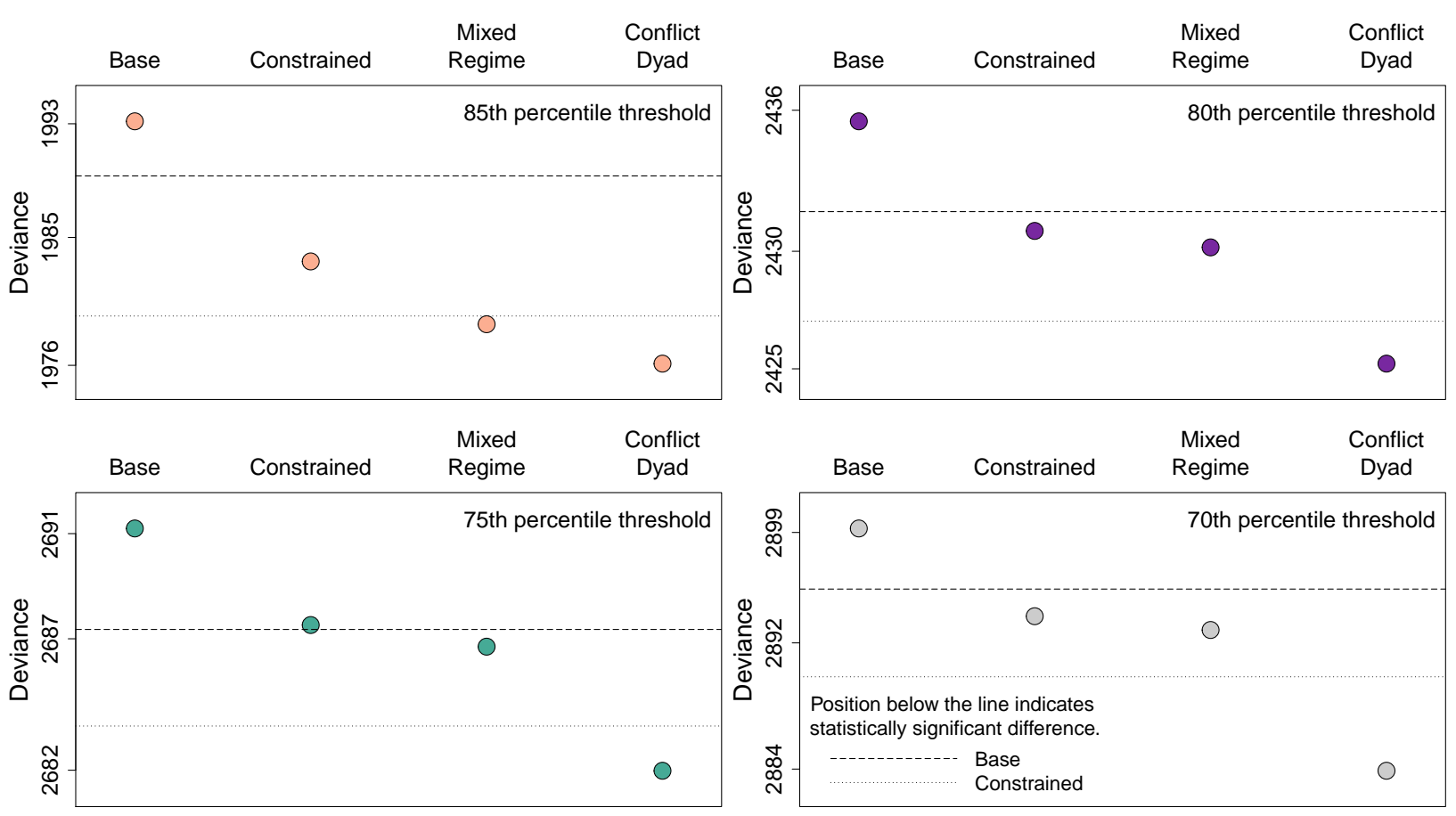

Figure A1: Deviance for all models using different threshold values. The 80th percentile threshold is reported in the main text. There are minor differences between thresholds, but the general pattern holds. Inclusion of the cross-layer term is a significant improvement over the baseline model, and allowing the effect of dyadic conflict to vary by track is a significant improvement of the constrained cross-layer model. 


\section{B Model Fit Diagnostics}
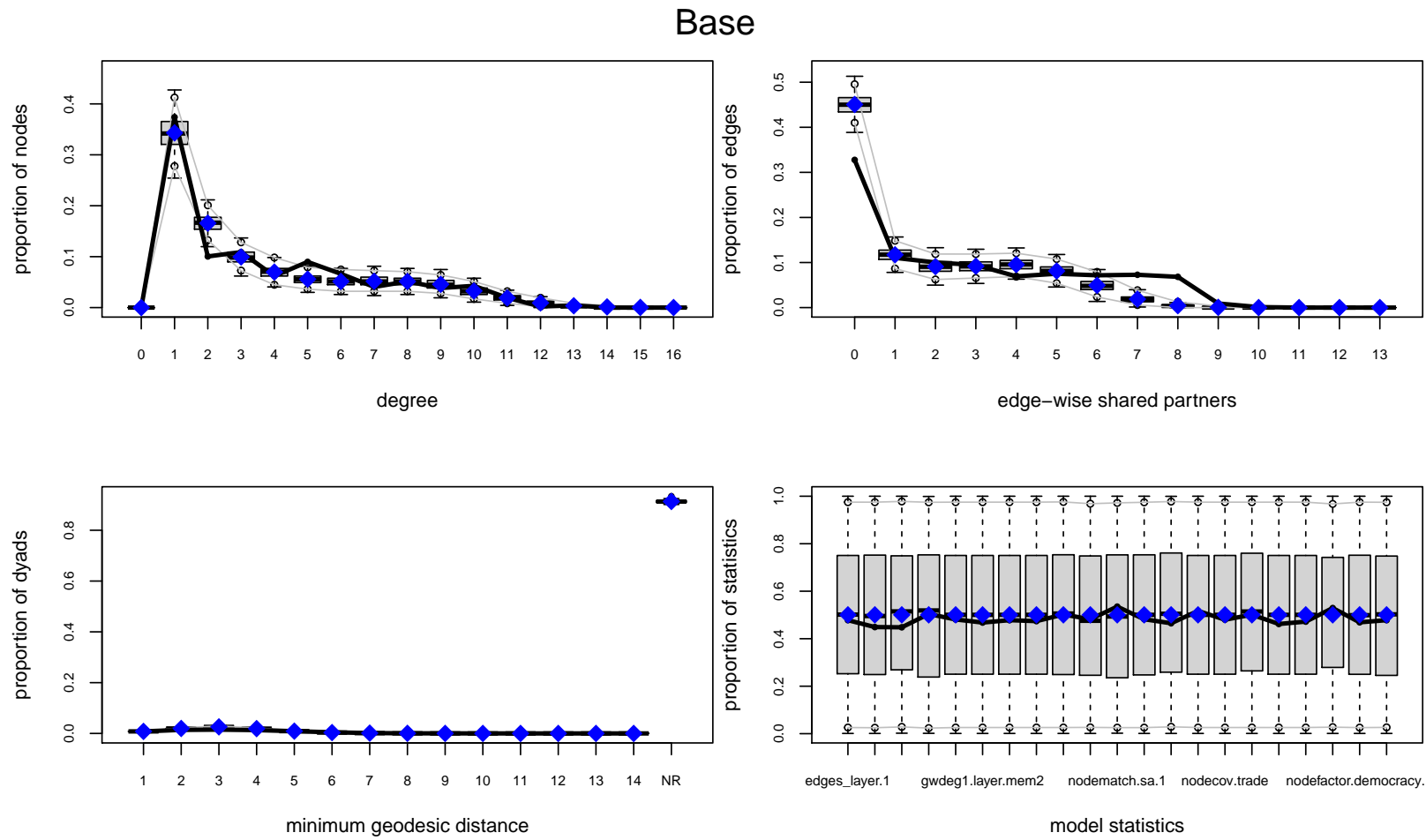

Constrained
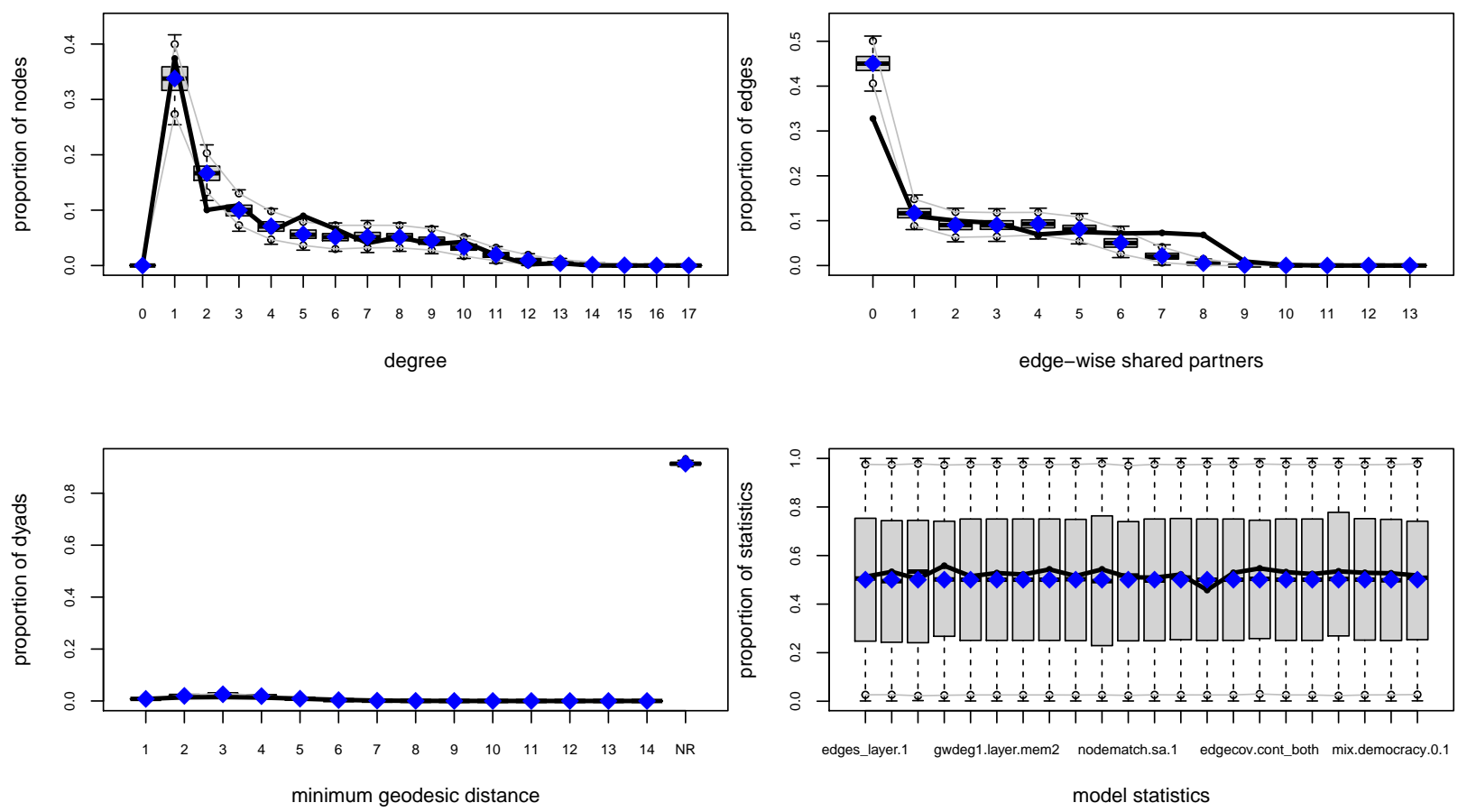

Figure B1: Model fit diagnostics for the base and constrained models. The black lines show observe statistics while the box-and-whisker plots show the distribution of statistics for model-simulated outcomes. The models slightly underestimates extreme levels of clustering, but otherwise perform well. 


\section{Mixed Regime}
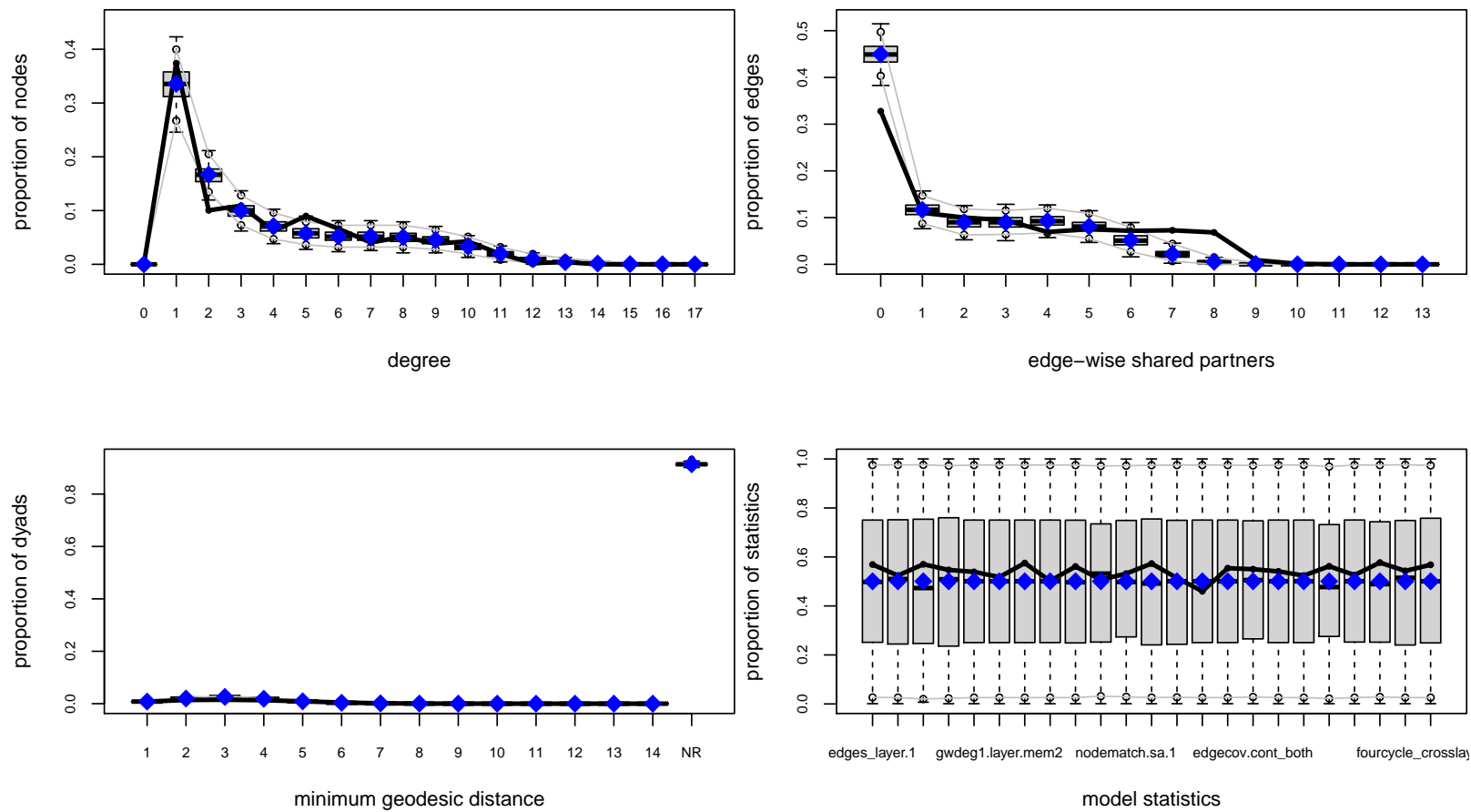

Conflict Dyad
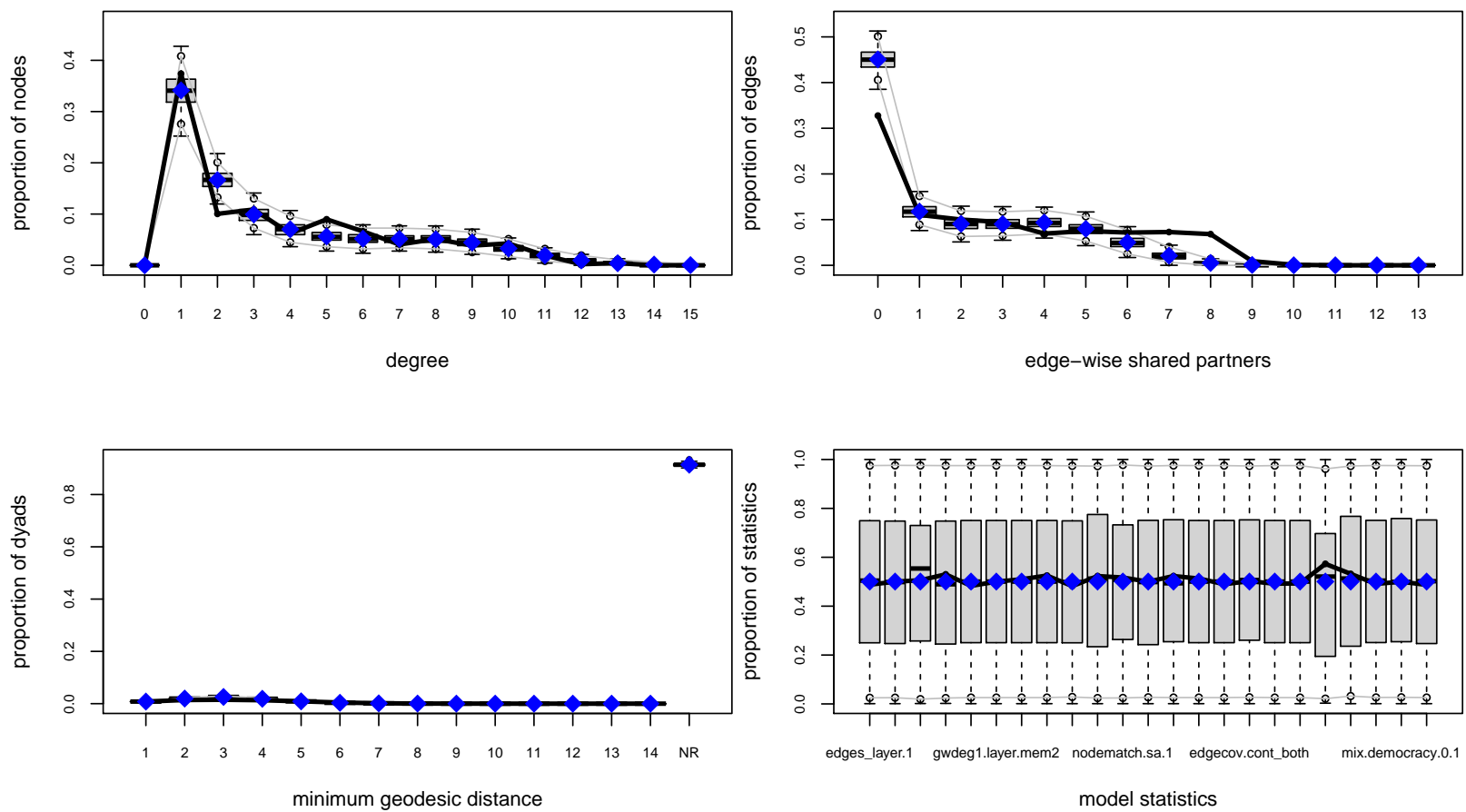

Figure B2: Model fit diagnostics for the mixed regime and conflict dyad models. The black lines show observe statistics while the box-and-whisker plots show the distribution of statistics for model-simulated outcomes. The models slightly underestimates extreme levels of clustering, but otherwise perform well. 